Article

\title{
Impact of Pus1 Pseudouridine Synthase on Specific Decoding Events in Saccharomyces cerevisiae
}

\author{
Bahar Khonsari and Roland Klassen *(D) \\ Institut für Biologie, Fachgebiet Mikrobiologie, Universität Kassel, Heinrich-Plett-Str. 40, D-34132 Kassel, \\ Germany; bahar.khonsari@gmail.com \\ * Correspondence: roland.klassen@uni-kassel.de
}

Received: 17 April 2020; Accepted: 5 May 2020; Published: 7 May 2020

\begin{abstract}
Pus1-dependent pseudouridylation occurs in many tRNAs and at multiple positions, yet the functional impact of this modification is incompletely understood. We analyzed the consequences of PUS1 deletion on the essential decoding of CAG (Gln) codons by tRNA ${ }^{\text {Gln }}$ CUG in yeast. Synthetic lethality was observed upon combining the modification defect with destabilized variants of tRNA ${ }^{\text {Gln }}$ CUG, pointing to a severe CAG-decoding defect of the hypomodified tRNA. In addition, we demonstrated that misreading of UAG stop codons by a tRNA ${ }^{\text {Gln }}$ CUG variant is positively affected by Pus1. Genetic approaches further indicated that mildly elevated temperature decreases the decoding efficiency of CAG and UAG via destabilized tRNA ${ }^{\text {Gln }}$ CAG variants. We also determined the misreading of CGC (Arg) codons by tRNA ${ }^{\text {His }}$ GUG, where the CGC decoder tRNA ${ }^{\text {Arg ICG contains }}$ Pus1-dependent pseudouridine, but not the mistranslating tRNA ${ }^{\text {His }}$. We found that the absence of Pus1 increased CGC misreading by tRNA ${ }^{\text {His }}$, demonstrating a positive role of the modification in the competition against non-synonymous near-cognate tRNA. Part of the in vivo decoding defects and phenotypes in pus1 mutants and strains carrying destabilized tRNA ${ }^{\mathrm{Gln}} \mathrm{CAG}$ were suppressible by additional deletion of the rapid tRNA decay (RTD)-relevant MET22, suggesting the involvement of RTD-mediated tRNA destabilization.
\end{abstract}

Keywords: tRNA modification; PUS1; pseudouridine; translation; non-sense suppression; sup70-65; misreading; rapid tRNA decay

\section{Introduction}

Pseudouridine $(\Psi)$ represents the most abundant tRNA modification and can be found within the acceptor stem, D-stem, anticodon stem loop, and the T-loop of tRNA [1-3]. Multiple $\Psi$ synthases are involved in the modification of specific positions, and defects in several of them are linked to human disease [3-5]. In yeast, the loss of individual $\Psi$ synthases may affect growth rate, global transcription of amino acid biosynthesis genes, and amino acid levels as well as lipid content [6-9]. Pus1 is a multisite $\Psi$ synthase that modifies tRNA positions 1,26,27,28,34,36,65, and 67 [10-13]. Despite the fact that several tRNAs are naturally modified by Pus1, some at multiple positions [14], yeast can tolerate the loss of Pus1 without growth defects at optimum temperature [11]. This suggests that under this condition, yeast translation operates at nearly normal efficiency even in the combined absence of all Pus1-dependent modifications. However, elevated temperature causes a noticeable growth delay of pus1-mutant cells [15]. In addition, pus1 mutation is known to result in synthetic lethality in yeast when combined with the loss of a second $\Psi$ synthase (Pus4), nuclear tRNA export protein Los1, or in cells carrying a mutant allele of tRNA ${ }^{\text {Gln }}$ CUG $(s l c 58)[11,16]$. These genetic interactions suggest that Pus1-dependent pseudouridylation becomes critical when other aspects of tRNA biogenesis or modification are disturbed. Strong negative genetic interactions of various tRNA modification genes in general support the idea of cooperativity and functional redundancy between different modifications, 
which may explain the weak phenotypes observed for many single-modification defects [15,17-23]. In humans, loss of Pus1 function is linked to the disorder MLASA (mitochondrial myopathy with lactic acidosis and sideroblastic anemia), which underscores the general importance of Pus1-dependent $\Psi$ formation [24].

A temperature-sensitive ( $t s$ ) growth defect is observed in several tRNA modification mutants $[15,18-20]$. In some cases, such a phenotype is caused by the temperature-dependent induction of a tRNA surveillance mechanism termed rapid tRNA decay (RTD) $[18,25]$. Activation of RTD at elevated temperatures results in highly specific destabilization of individual tRNAs, and the concomitant tRNA depletion causes the inability to grow in this condition. RTD involves exonucleases Rat1 and Xrn1 and is strongly inhibited upon deletion of MET22, a gene involved in sulfur assimilation [26]. The inhibitory function of met 22 mutation occurs due to the accumulation of pAp (adenosine $3^{\prime}, 5^{\prime}$ bisphosphate), a sulfur assimilation byproduct inhibiting both of the RTD-relevant exonucleases [26,27]. Hence, met 22 mutation suppresses growth defects of several tRNA modification mutants linked to RTD and inhibits the active destabilization of specific tRNAs [26].

To better characterize the in vivo role of Pus1 in tRNA function, we tested the requirement of the synthase for specific decoding events in yeast and determined the dependency of phenotypes associated with pus1 mutation or destabilized tRNA ${ }^{\text {Gln }}$ CUG variants on the RTD factor MET22. We demonstrated that two additional variants of tRNA ${ }^{\text {Gln }}$ CUG caused synthetic lethality when combined with a pus1 mutation. This effect, as well as individual phenotypes of the modification defect and the destabilized tRNA, were suppressed in the absence of MET22. Furthermore, specific decoding defects occurred in cells lacking Pus1-dependent pseudouridylation, and some of these were also ameliorated in absence of MET22. Our study implies Pus1-dependent $\Psi$ as an RTD-relevant modification that becomes critical for tRNA ${ }^{\text {Gln }}$ CUG function when different stem regions are destabilized.

\section{Materials and Methods}

\subsection{Strains and Plasmids}

The yeast strains used in this study are listed in Table 1. Yeast was grown in yeast peptone dextrose (YPD) medium or in yeast nitrogen base (YNB) minimal medium lacking specific nutrients such as uracil or individual amino acids [28]. The latter medium was used to select for plasmids, DNA fragments for gene deletion, or to diagnose changes in auxotrophies. Gene deletions were obtained via lithium-acetate-mediated transformation [29] using PCR products in which marker genes from pUG6, pUG27, pUG72, or pUG73 were flanked with 50 nucleotides identical to target genes as described [30]. Correct integration of such gene deletion cassettes was verified using diagnostic PCR according to Reference [30]. Oligonucleotides used are listed in Table S1. HIS3-selected plasmids for single copy expression of SUP70, sup70-65, and sup70-33 (pSUP70, pSUP70-33, pSUP70-65) were described previously [31]. To study the complementation of sup70, we first generated a SUP70 gene deletion in the presence of pAK01 (SUP70-CEN-URA3), and then introduced either pSUP70, pSUP70-33, or pSUP70-65 [31]. For multicopy expression of $t Q(U U G)$, the tRNA gene was subcloned from YEplacQ [32] into pRS423 using EcoRI and SalI, creating pRK51. A similar pRS425-based construct has been described [33]. Overexpression of SUP70 involved pSUP70 2 $\mu$ [31]. To study the ability to lose pAK01, strains were first streaked from selective histidine- and uracil-free YNB medium to non-selective YPD medium and incubated for $24 \mathrm{~h}$. Next, cells were recovered from the plates, washed with sterile water, and applied to uracil-free YNB and YNB medium containing uracil and 5-fluoro-orotate (5-FOA). Plates were incubated at $30^{\circ} \mathrm{C}$. Rescue of integrated auxotrophic marker genes was done using transient expression of CRE recombinase using constructs and procedures described previously [30]. 
Table 1. Strains used in this study.

\begin{tabular}{|c|c|c|}
\hline Strain & Genotype & Reference \\
\hline BY4741 & MATa, his3, leu2, met15, ura3 & Euroscarf, Frankfurt \\
\hline met22 & BY4741 met22::KANMX4 & Euroscarf, Frankfurt \\
\hline pus1 & BY4741 pus1::KANMX4 & Euroscarf, Frankfurt \\
\hline W303-1B & MAT $\alpha$ leu2-3,112 trp1-1 can1-100 ura3-1 ade2-1 his3-11,15 & [34] \\
\hline RK134 & BY4741 tQ(CUG)::KlLEU2 pSUP70-65 & this work \\
\hline RK135 & BY4741 tQ Q(CUG)::KlLEU2 pSUP70-33 & this work \\
\hline RK143 & BY4741 tQ(CUG)::KlLEU2 pSUP70 & this work \\
\hline RK172 & BY4741 tQ(CUG)::KlLEU2 pAK01 & this work \\
\hline RK289 & BY4741 tQ(CUG)::loxP pAK01 & this work \\
\hline RK356 & BY4741 tQ(CUG)::KlLEU2 pRK51 & this work \\
\hline RK643 & BY4741 tQ(CUG)::KlLEU2 pSUP70-33 met22::KlURA3 & this work \\
\hline RK644 & BY4741 tQ(CUG)::KlLEU2 pSUP70-65 met22::KIURA3 & this work \\
\hline RK645 & BY4741 tQ(CUG)::loxP pAK01 pus1::KlLEU2 & this work \\
\hline RK648 & BY4741 tQ(CUG)::loxP pSUP70 & this work \\
\hline RK649 & BY4741 tQ(CUG)::loxP pSUP70-33 & this work \\
\hline RK650 & BY4741 tQ $(C U G):: l o x P$ pSUP70-65 & this work \\
\hline RK651 & BY4741 tQ(CUG)::loxP pSUP70 pus1::KlLEU2 & this work \\
\hline RK655 & BY4741 tQ(CUG)::loxP pAK01 pus1::KlLEU2 met22::KANMX4 & this work \\
\hline RK666 & BY4741 tQ(CUG)::loxP pAK01 met22::KlLEU2 & this work \\
\hline RK668 & BY4741 tQ(CUG)::loxP pRK51 & this work \\
\hline RK669 & BY4741 tQ(CUG)::loxP pRK51 pus1::KlLEU2 & this work \\
\hline RK452 & W303-1B pus1::KILEU2 & this work \\
\hline RK703 & W303-1B met22::KIURA3 & this work \\
\hline RK704 & W303-1B pus1::KlLEU2 met22::KIURA3 & this work \\
\hline RK499 & BY4741 pus1::SpHIS5 & this work \\
\hline RK567 & BY4741 pus1::SpHIS5 met22::KlLEU2 & this work \\
\hline RK475 & BY4741 deg1::SpHIS5 & this work \\
\hline RK658 & BY4741 deg1::SpHIS met22::KlLEU2 & this work \\
\hline
\end{tabular}

\subsection{Growth Phenotype}

For phenotyping assays, yeast strains were first grown on solid YPD or plasmid-selective YNB medium for 24 to $36 \mathrm{~h}$. Suspensions of cells were prepared by resuspending cell material recovered from the plates in sterile water. Cell densities were determined photometrically and adjusted to an $\mathrm{OD}_{600 \mathrm{~nm}}$ of 1.5. Ten-fold serial dilutions were prepared in sterile water and subsequently spotted on YPD or YNB minimal media. For temperature-sensitivity tests, identical replicates of plates from the same set of cell dilutions were incubated at different temperatures and photographed after $2-4$ days.

\subsection{RNA Isolation and Reverse Transcription}

Total RNA was isolated from yeast strains grown to $\mathrm{OD}_{600 \mathrm{~nm}}=1$ using NucleoZOL (Macherrey-Nagel, Düren, Germany). Two micrograms of total RNA was treated with RNase-free DNase (Thermo scientific, Waltham, USA) in $1 \times$ reaction buffer containing $\mathrm{MgCl}_{2}$ (reaction volume of $20 \mu \mathrm{L}$ ) for $30 \mathrm{~min}$ at $37^{\circ} \mathrm{C}$. After addition of $2 \mu \mathrm{L} 50 \mathrm{mM}$ EDTA, samples were heated to $65^{\circ} \mathrm{C}$ for $10 \mathrm{~min}$. For first-strand cDNA synthesis, $0.9 \mu \mathrm{L}$ of DNase treated samples were incubated with 15 oligo $\mathrm{O} 166$ and $\mathrm{O} 1550$ (Table S1) in a total volume of $12 \mu \mathrm{L}$. Samples were heated to $65^{\circ} \mathrm{C}$ for $5 \mathrm{~min}$, chilled on ice, and reaction buffer, RNase inhibitor, dNTPs, and reverse transcriptase added as recommended in the instructions of the RevertAid first strand cDNA synthesis kit (Thermo Scientific). For each RNA sample, a control reaction omitting the reverse transcriptase was prepared. Amplification of cDNAs specific for tRNA Gly GCC and sup70-33 was carried out using $0.5 \mu \mathrm{L}$ of cDNA or control reaction and oligos O165/O166 or O171/O1550 (Table S1) in a reaction volume of $20 \mu \mathrm{L}$ with DreamTaq polymerase (Thermo Scientific). Reactions were separated on a $2 \%$ agarose gel. 


\subsection{Quantification of Misreading}

In vivo mistranslation rates of the CGC (Arg) codon by tRNA ${ }^{\text {His }}$ GUG were determined using dual luciferase plasmids pDB688 (control) and pDB868 (H245R) [35]. Both plasmids were introduced into BY4741 wild-type, pus1, and pus1 met22 double mutants. Resulting strains were grown in uracil-free YNB overnight at either $30^{\circ} \mathrm{C}$ or $37^{\circ} \mathrm{C}$ and in the presence or absence of $200 \mu \mathrm{g} / \mathrm{mL}$ paromomycin. Renilla/firefly luminescence was measured using the dual luciferase reporter assay kit (Promega, Fitchburg, USA) and a Glomax luminometer (Promega). Six to eight biological replicates were conducted for each strain and condition and mistranslation rates were calculated by normalizing the firefly H245R activity to the upstream renilla luciferase of the same construct and then normalizing to the activity ratio of the two luciferases from the control construct in the same genetic background.

\section{Results}

\subsection{Yeast Reporter Strains for CAG Decoding by $t R N A^{G l n} U U G$ or $t R N A{ }^{G l n} C U G$}

In yeast, the CAG (Gln) codon decoding tRNA ${ }^{\text {Gln }} \mathrm{CUG}$ is encoded by a single essential gene (SUP70) (Figure 1A) [36]. SUP70 alleles sup70-33 and sup70-65 form tRNA ${ }^{\text {Gln } C U G ~ v a r i a n t s ~ w h i c h ~}$ exhibit reduced stability and charging efficiency in vivo but provide sufficient CAG decoding activity to sustain viability in the absence of native SUP70 $[31,37,38]$. These tRNA ${ }^{\text {Gln }} \mathrm{CUG}$ variants contain base exchanges G31A (sup70-65) and G68A (sup70-33), destabilizing the acceptor- and anticodon-stems, respectively (Figure 1A). Inviability of sup 70 mutants can also be suppressed by overexpression of the inefficient CAG decoder tRNA ${ }^{\text {Gln } U U G ~[39] . ~ I n ~ o r d e r ~ t o ~ a s s e s s ~ t h e ~ i n ~ v i v o ~ C A G ~ d e c o d i n g ~ p o t e n t i a l ~}$ of tRNA ${ }^{\text {Gln }}$ UUG, sup70-33 and sup70-65 in the absence of Pus1-dependent $\Psi$, we generated plasmid shuffle strains containing a sup 70 deletion complemented with a counter-selectable URA3 construct carrying native SUP70. To this background, a PUS1 deletion was introduced as well as HIS3-selected constructs providing either SUP70, sup70-33, or sup70-65 in single copy (s.c.) or the tRNA ${ }^{\text {Gln }}$ UUG gene $t Q(U U G)$ in multicopy (h.c.). Upon 5-fluoro-orotate (5-FOA)-mediated chase out of the SUP70-URA3 vector, the sup70 complementation efficiency of these tRNA genes was inferred by monitoring growth on 5-FOA-supplemented medium (Figure 1B).

As shown in Figure 1C, the inviability of sup70 mutants with the SUP70-URA3 plasmid on 5-FOA medium demonstrated that the plasmid indeed could not be lost from a sup70 strain unless another SUP70 plasmid (SUP70-HIS3), which was retained on 5-FOA medium, was present. While either SUP70 or the destabilized variants sup70-33 and sup70-65 were sufficient for complementation in the wild-type background, mutation of PUS1 ablated the sup 70 complementation ability of the destabilized variants without affecting complementation by native SUP70 (Figure 1D). This result indicates that absence of Pus1-dependent $\Psi$ weakened the ability of the destabilized tRNA ${ }^{\text {Gln }}$ CUG variants to carry out cognate CAG decoding, which is the essential function of SUP70. When the complementation of sup70 by multicopy expression of tQ(UUG) was analyzed, no difference between sup70 and sup70 pus1 strains was observed (Figure 1E). Since the pus1 mutation is correlated with temperature sensitivity, we confirmed the presence of this phenotype in the sup70 pus1 strains (Figure 1E). Hence, in contrast to the tRNA ${ }^{\text {Gln }} \mathrm{CUG}$ variants providing reduced CAG-decoding potential, the inefficient CAG-decoding function of tRNA ${ }^{\text {Gln }}$ UUG was not further impaired in the absence of Pus1. 

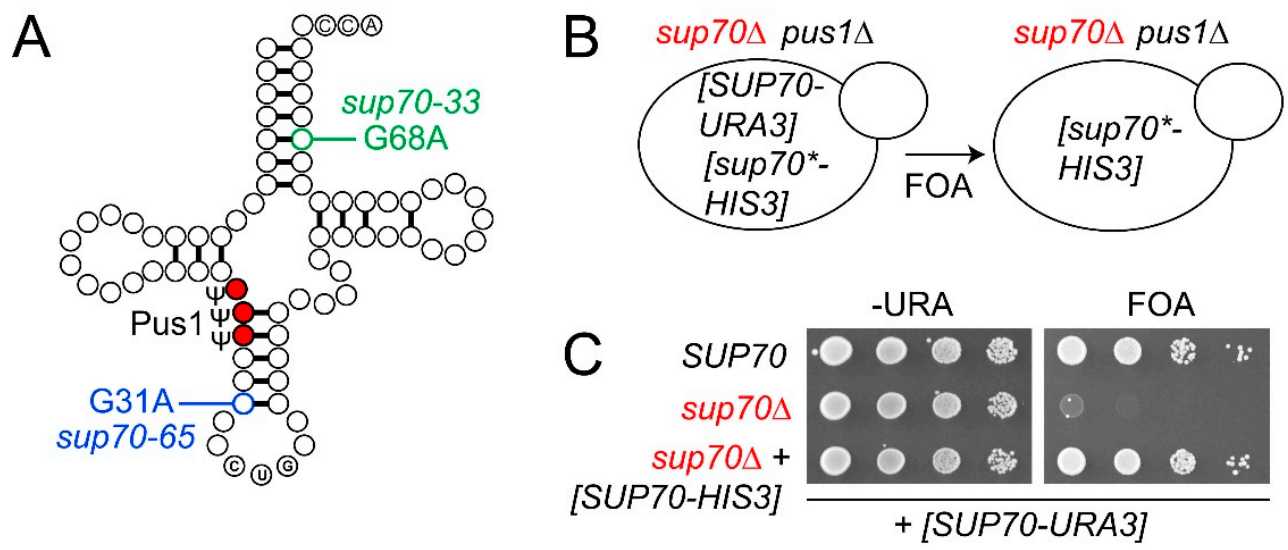

D

\begin{tabular}{|c|c|c|c|c|c|c|c|c|c|c|}
\hline \multicolumn{2}{|c|}{ strain } & \multirow[t]{2}{*}{$\begin{array}{l}\text { s.c. vector } \\
\text { HIS3 }\end{array}$} & \multicolumn{4}{|c|}{-URA } & \multicolumn{4}{|c|}{ FOA } \\
\hline PUS1 & SUP70 & & 0 & 0 & 0 & $\mathrm{O}$ & 0 & 0 & $\$$ & . \\
\hline PUS1 & sup70 & SUP70 & 0 & 0 & 0 & 8 & 0 & 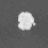 & $\%$ & $\approx$ \\
\hline PUS1 & sup70 & sup70-33 & 0 & 0 & 0 & 6 & 0 & 8 & 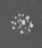 & \\
\hline PUS1 & sup70 $\Delta$ & sup70-65 & 0 & 0 & 0 &  & 0 & 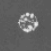 & $*$ & \\
\hline pus1A & sup70A & SUP70 & 0 & 0 & 0 & 난 & 0 & 0 & $\oplus$ & 8 \\
\hline pus1 $1 \Delta$ & sup70 $\Delta$ & sup70-33 & 0 & 0 & 0 & D & 0 & & & \\
\hline pus1A & sup70 & sup70-65 & 0 & 0 & 0 & 8 & O & & & \\
\hline
\end{tabular}

$+[$ SUP70-URA3]

\begin{tabular}{|c|c|c|c|c|c|c|c|c|c|}
\hline \multicolumn{2}{|c|}{ strain } & $\begin{array}{l}\text { s.c./h.c. vector } \\
\text { HIS3 }\end{array}$ & YPD $30^{\circ} \mathrm{C}$ & YPD $39^{\circ} \mathrm{C}$ & -URA & \multicolumn{4}{|c|}{ FOA } \\
\hline PUS1 & SUP70 & & & 00 & 000 & 0 & $\overline{0}$ & 0 & 3 \\
\hline PUS1 & sup70A & & & 00 政 & 0000 & 0 & & & \\
\hline PUS1 & sup70 & s.c. SUP70 & 00 & 000 & 000 & 0 & 0 & - & $\$$ \\
\hline PUS1 & sup70 $\Delta$ & h.c. empty & & 000 秋 & 000 & 0 & & & \\
\hline PUS1 & sup70 & h.c. $t Q(\cup \cup G)$ & 000 & 000 䌃 & 000 & 0 & 중 & $A$ & \\
\hline pus1 $1 \Delta$ & sup70 $\Delta$ & s.c. SUP70 & 000 & 00 & $000=$ & 0 & 0 & - & $x$ \\
\hline pus1 & sup70A & h.c. empty & & 00 & 000 & 0 & & & \\
\hline pus1A & sup70 & h.c. $t Q(\cup \cup G)$ & & & 000 & 0 & s & 4 & \\
\hline
\end{tabular}

$+[S U P 70-U R A 3]$

Figure 1. Complementation of sup70 mutation by sup70-33, sup70-65, and $t Q(U U G)$ in presence and absence of PUS1. (A) Scheme depicting tRNA Gln CUG with base exchanges present in sup70-33 and sup70-65 alleles, as well as Pus1-dependent pseudouridylation sites highlighted. (B) Outline of plasmid shuffle approach. Yeast strains carrying a deletion of SUP70 and 5-fluoro-orotate (5-FOA) counter-selectable SUP70 plasmids [SUP70-URA3] were used. In addition, HIS3-selected plasmids were introduced, which carry either native SUP70 or sup70-33/sup70-65 alleles [sup70*-HIS3]. The complementation ability of the HIS3-selected plasmids was determined in the presence or absence of a genomic PUS1 deletion. (C) Proof of principle assay demonstrating inviability of the reporter strain (sup70 [SUP70-URA3]) on 5-FOA medium (FOA) in the absence of native SUP70 ([SUP70-HIS3]). (D) Complementation of sup70 by SUP70, sup70-33, and sup70-65 in the presence and absence of PUS1. Relevant strain genotype is indicated (strain). s.c.: single copy. (E) Complementation of sup70 by high-copy (h.c.) $t Q(U U G)$ or single copy (s.c.) $S U P 70$ in the presence and absence of PUS1. h.c. empty: empty vector. 


\subsection{Role of MET22 in pus1 and sup70-33/sup70-65 Phenotypes}

Previously, we observed a strong temperature-sensitive growth $(t s)$ phenotype in yeast cells relying on the sup70-65 variant for CAG decoding [40]. We reconfirmed this result and further demonstrated that sup70-33 is also linked to a robust ts phenotype (Figure 2A). Similarly, mutation of PUS1 is correlated with a milder ts phenotype that slows growth at $38^{\circ} \mathrm{C}$ and above [15] (Figure $2 \mathrm{~B}$ ). In some cases, the absence of core modifications in tRNA may trigger degradation by rapid tRNA decay (RTD), which is induced by mild heat stress [18]. To test whether the observed ts phenotypes in sup70-33, sup70-65, and pus1 mutants could be attributable to RTD, we combined these mutations with a met 22 deletion and compared growth at elevated temperatures between the MET22 parental strains and the met 22 derivatives. As shown in Figure 2A, the ts phenotypes of strains carrying sup70-33 or sup70-65 as the sole SUP70 variant were partially rescued by deletion of MET22. While the sup70-65 strain was severely growth-impaired at $35{ }^{\circ} \mathrm{C}$, the sup70-65 met 22 strain exhibited much more robust growth in this condition. A similar improvement was seen for the sup70-33 met22 strain at $37^{\circ} \mathrm{C}$ (Figure $2 \mathrm{~A}$ ). Likewise, an improvement of growth at temperatures above $37^{\circ} \mathrm{C}$ was observable in the pus1 met22 double mutant as compared to the single mutants (Figure 2B). In contrast to pus1, we found that loss of the Deg1 $\Psi$ synthase modifying U38 and U39 [6] was linked to a MET22-independent ts phenotype (Figure S1). Thus, destabilized tRNA ${ }^{\text {Gln } C U G ~ v a r i a n t s ~ a n d ~ p u s 1 ~ m u t a n t s ~ e x h i b i t ~} t$ growth phenotypes that could in part result from activation of RTD, while the phenotype associated with deg1 mutation may result from RTD independent effects. We further tested whether the ts phenotype of pus1 mutants might be mainly due to functional defects in $t R N A{ }^{\text {Gln }}$ by overexpressing both isoacceptor $t R N A s$. However, the presence of elevated copy numbers of $t Q(C U G)$ and $t Q(U U G)$ alone or in combination was insufficient to suppress the pus1 phenotype (Figure S2).

\begin{tabular}{|c|c|c|c|c|c|c|c|c|c|c|c|c|c|}
\hline plasmid & \multicolumn{2}{|c|}{ strain } & \multicolumn{4}{|c|}{$30^{\circ} \mathrm{C}$} & \multicolumn{4}{|c|}{$35^{\circ} \mathrm{C}$} & \multicolumn{2}{|r|}{$37^{\circ} \mathrm{C}$} & $39^{\circ} \mathrm{C}$ \\
\hline & SUP70 & MET22 & & 0 & 0 象 & & 0 & 0 & 0 & & & 00 & 00 \\
\hline & SUP70 & met22 & 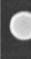 & 0 & - 6 & & 0 & 0 & & 4 & 0 & 00 解 & 00 \\
\hline SUP70 & sup $70 \Delta$ & MET22 & 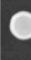 & 0 & 0 & & 0 & 0 & 0 & 8 & 0 & 00 今 & 00 \\
\hline sup70-33 & $\sup 70 \Delta$ & MET22 & 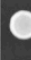 & 0 & 0 缕 & & 0 & 0 & . & 4 & 0 & 8 & 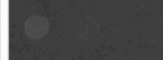 \\
\hline sup70-33 & sup70A & met22 $2 \Delta$ & C & 0 & (2) 연 & & 0 & 0 & & \% & & 00 & 0 \\
\hline sup70-65 & sup $70 \Delta$ & MET22 & 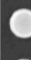 & 0 & 0 ; & & 0 & - & & & 0 & & 0 \\
\hline sup70-65 & sup70 & met22 & 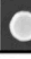 & 0 & C & & 은 & 0 & 5 & 4 & & ( & 0 \\
\hline
\end{tabular}

B

\begin{tabular}{|c|c|c|c|c|c|c|c|c|c|c|c|c|c|c|}
\hline \multicolumn{2}{|c|}{ strain } & \multicolumn{4}{|c|}{$30^{\circ} \mathrm{C}$} & \multicolumn{4}{|c|}{$37^{\circ} \mathrm{C}$} & \multicolumn{3}{|c|}{$39^{\circ} \mathrm{C}$} & \multicolumn{2}{|r|}{$40^{\circ} \mathrm{C}$} \\
\hline PUS1 & MET22 & 0 & 0 & 0 & & 0 & O & 0 & & 0 & 0 & 8 & & 0 \\
\hline PUS1 & met22 & 0 & & 0 & 6 & & 0 & 0 & 당 & 0 & 0 & - & 0 & 0 \\
\hline pus1A & MET22 & 0 & 0 & o & s & 0 & 0 & 0 & 8 & ○ & 0 & & 0 & \\
\hline pus1s & met22 $2 \Delta$ & 0 & o & 0 & 3 & 0 & 0 & 0 & 8 & 0 & 0 & 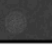 & 0 & 0 \\
\hline
\end{tabular}

Figure 2. Thermosensitive growth phenotypes of sup70-65, sup70-33, and pus1 strains are partly suppressed by deletion of MET22. (A) Growth of wild-type (SUP70 MET22), met22, and sup70-33/sup70-65 mutants with and without met22 deletion at elevated temperatures. Mutants carrying sup70-33 or sup70-65 as sole source of tRNA ${ }^{\text {Gln }}$ CUG were generated by complementing a genomic sup70 deletion (sup70 4 ) with plasmid-borne sup70-33 or sup70-65, respectively. For control purposes, native SUP70 was provided from the same vector backbone (sup70 $S U P 70)$. Plasmids used are indicated in the column labeled "plasmid". (B) Growth of wild-type (PUS1 MET22), met22 and pus1 single mutants, and pus 1 met 22 double mutants at elevated temperatures. 


\subsection{Effect of met22 Mutation on Abundance of sup70-33 tRNA}

The suppression of ts phenotypes of the destabilized SUP70 variants by met22 suggested the involvement of RTD-like mechanisms in the destabilization process. Since not only loss of modifications but also destabilized stem regions in tRNA can trigger RTD [41-44], we further explored the possibility that sup70-33 tRNA may be destabilized by this surveillance mechanism. We utilized a reverse-transcriptase-based assay that specifically amplified cDNA from the sup70-33 tRNA without detecting the nearly identical tRNA ${ }^{\text {Gln }}$ UUG (Figure S3). This assay made use of the sup70-33-specific G68A base change which is not present in tRNA ${ }^{\text {Gln }}$ UUG. Next, we employed this assay to monitor cDNA generation efficiency with identical amounts of total RNA derived from sup70-33 strains with and without the met 22 mutation either grown at $30^{\circ} \mathrm{C}$ or shifted to $37^{\circ} \mathrm{C}$ for $5 \mathrm{~h}$. As shown in Figure 3 , the sup70-33 cDNA signal declined in the $37^{\circ} \mathrm{C}$ culture as compared to the $30{ }^{\circ} \mathrm{C}$ culture, while a control cDNA for tRNA ${ }^{\text {Gly }}$ GCC remained unaffected. Further, we observed elevated cDNA formation for sup70-33 when MET22 was mutated at both $30^{\circ} \mathrm{C}$ and $37^{\circ} \mathrm{C}$. These results revealed that sup $70-33$ is destabilized in a temperature- and MET22-dependent manner, conditions commonly observed for well-studied RTD cases [26,41,42].

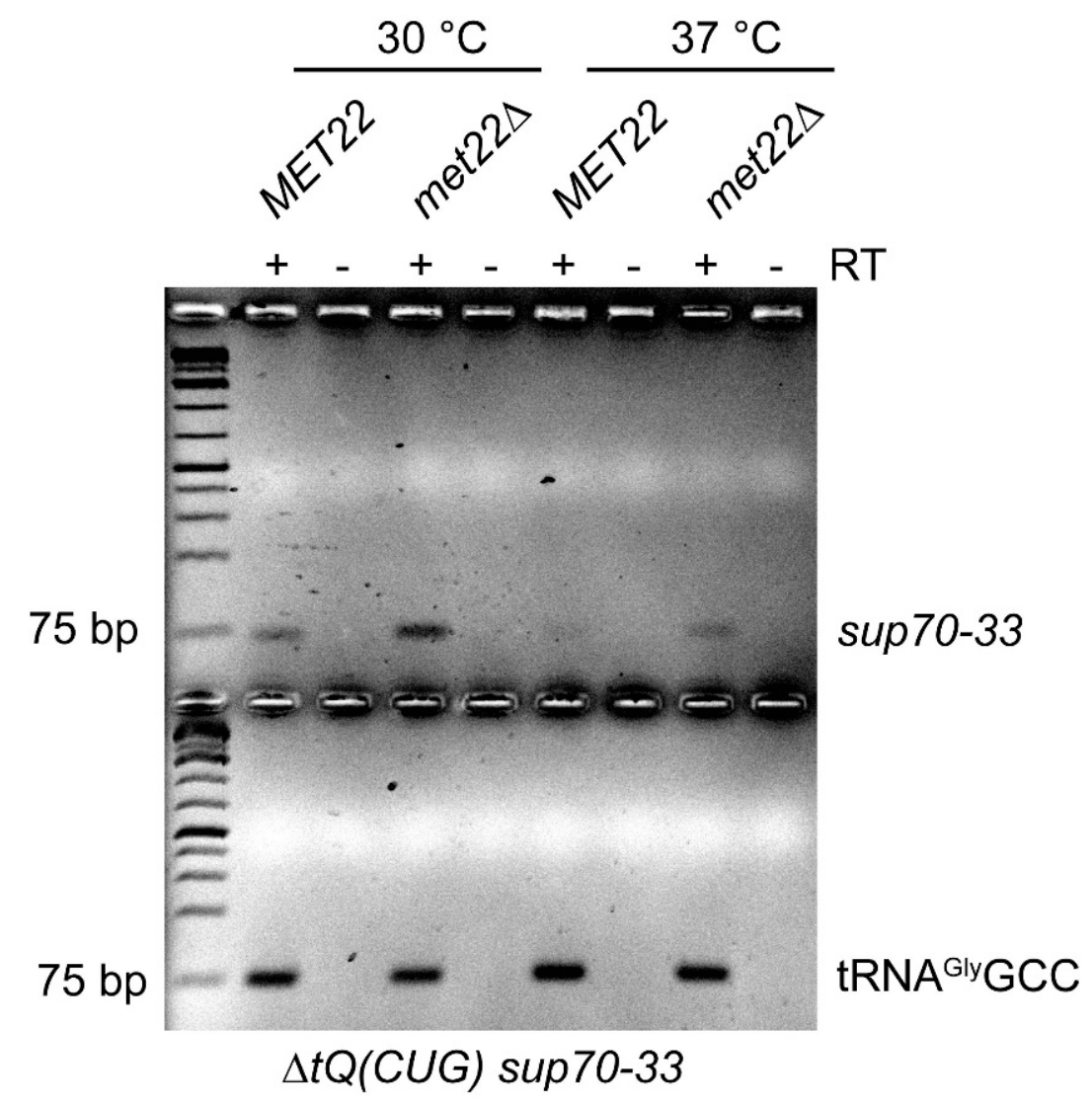

Figure 3. Impact of met22 mutation on sup70-33 abundance. Total RNA was isolated from sup70-33 mutants with or without the met 22 mutation, grown at $30^{\circ} \mathrm{C}$ or shifted to $37^{\circ} \mathrm{C}$ for $5 \mathrm{~h}$ as indicated. Identical amounts of RNA were reverse-transcribed (RT+) to cDNA using oligonucleotides specific for sup70-33 and tRNA Gly GCC, respectively. For control purposes, identical reactions were carried out omitting the reverse transcriptase (RT-). Low-cycle-number PCR was used to amplify cDNAs from sup70-33 and tRNA Gly GCC and reactions were separated on a $\%$ agarose gel. The 75 bp band of the DNA marker used is indicated. 


\subsection{Suppression of Synthetic Lethal Genetic Interaction between Destabilized sup70 Variants and PUS1}

Since negative consequences of PUS1 deletion and either sup70-33 or sup70-65 are individually suppressed by deletion of the RTD factor MET22 (Figure 2), we investigated whether the synthetic lethality caused by combining the tRNA modification defect with the sup70 variants was suppressible by met 22 mutation as well. We used the plasmid shuffle approach described above (Figure 1) in strains that carried either a MET22 wild-type allele or a genomic deletion. As shown in Figure 1D, pus1 sup70 double mutants with the SUP70-URA3 construct were able to grow on 5-FOA medium when wild-type SUP70 was provided by a second plasmid, but not with sup70-33 or sup70-65. However, we observed that this requirement for native SUP70 was bypassed upon deletion of MET22 (Figure 4). In the triple pus1 sup70 met22 mutant containing the SUP70-URA3 plasmid, either form of SUP70 (including the destabilized variants) permitted growth on 5-FOA medium (Figure 4). Thus, the synthetic lethality of pus1 sup70-33/sup70-65 was suppressed by the RTD-ablating met22 mutation.

\begin{tabular}{|c|c|c|c|c|c|c|c|c|c|}
\hline \multicolumn{3}{|c|}{ strain } & $\begin{array}{l}\text { s.c. vector } \\
\text { HIS3 }\end{array}$ & \multicolumn{3}{|c|}{-URA } & \multicolumn{3}{|c|}{ FOA } \\
\hline PUS1 & MET22 & SUP70 & & 00 & 0 & 0 & 0 & 0 & 0 \\
\hline PUS1 & MET22 & $\sup 70 \Delta$ & & 00 & 0 & 하 & & & \\
\hline PUS1 & MET22 & $\sup 70 \Delta$ & SUP70 & 00 & 0 & 急 & 0 & 0 & 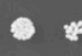 \\
\hline PUS1 & MET22 & sup70 & sup70-65 & 00 & 0 & $\Leftrightarrow$ & - & (6) & \& \\
\hline pus1 & MET22 & sup70 7 & SUP70 & 00 & 0 & $B$ & 0 & 0 & $\bullet$ \\
\hline pus1s & MET22 & $\sup 70 \Delta$ & sup $70-65$ & 00 & 0 & $\theta$ & 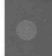 & & \\
\hline pus1 $1 \Delta$ & met22 $\Delta$ & sup70 & SUP70 & 00 & 0 & 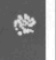 & 0 & 0 & - \\
\hline pus1A & met22 & sup70 & sup70-65 & 00 & 0 & 85: & 0 & - & 4 \\
\hline
\end{tabular}

\begin{tabular}{|c|c|c|c|c|c|c|c|c|c|c|}
\hline B & strain & & $\begin{array}{l}\text { s.c. vector } \\
\text { HIS3 }\end{array}$ & & URA & & & & OA & \\
\hline PUS1 & MET22 & SUP70 & & 0 & 0 & 8 & 10 & 0 & 0 & 4 \\
\hline PUS1 & MET22 & sup70A & & 0 & 0 & क & & & & \\
\hline PUS1 & MET22 & sup70A & SUP70 & 0 & 0 & 8 & $c$ & 0 & 0 & 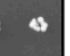 \\
\hline PUS1 & MET22 & sup70A & sup70-33 & 0 & - 0 & 8 & - & 0 & 4 & 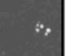 \\
\hline pus1A & MET22 & $\sup 70 \Delta$ & SUP70 & 0 & 0 & s & e & 0 & $\bullet$ & 4 \\
\hline pus1 $1 \Delta$ & MET22 & $\sup 70 \Delta$ & sup70-33 & 0 & 00 & 2 & & & & \\
\hline pus1A & met22 & sup $70 \Delta$ & SUP70 & 100 & 00 & क & 0 & 0 & $\bullet$ & 8 \\
\hline pus1A & met22 & $\sup 70 \Delta$ & sup70-33 & 00 & 00 & 車 & $\mathrm{c}$ & 0 & $\approx$ & \\
\hline
\end{tabular}

Figure 4. Synthetic lethal interaction between pus1 and sup70-33/sup70-65 was suppressed by met22 mutation. (A) Plasmid shuffle approach (as in Figure 1) for analysis of sup70 complementation by SUP70 or sup70-65 in absence of PUS1 (pus1D), MET22 (met22A), or both. All strains carried the [SUP70-URA3] plasmid. Indicated strains additionally carried HIS3-plasmids (s.c. vector HIS3) providing SUP70 or sup70-65 as indicated. Top: wild-type BY4741. (B) Plasmid shuffle approach for analysis of sup70

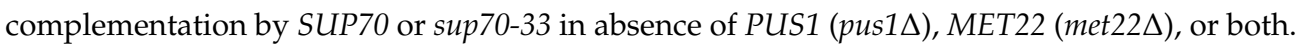

\subsection{Role of PUS1 and MET22 in UAG Misreading by sup70-65 at Different Temperatures}

The sup70-65 variant of tRNA ${ }^{\text {Gln }}$ CUG exhibits a well characterized ability to misread UAG stop codons via first codon position U/G wobble pairing [31,38]. The efficiency of this decoding event can be scored in yeast strains carrying a premature UAG stop codon within the tryptophan biosynthesis gene TRP1 (trp1-1 allele). In such strains, UAG misreading reverted the inability to grow on tryptophan-free 
medium (trp-) (Figure 5A). In order to assess how elevated temperature and loss of Pus1 influenced the efficiency of sup70-65 in UAG misreading, we introduced pus1 and met22 deletions into a reporter strain carrying the trp1-1 allele and subsequently expressed sup70-65 in single copy (s.c.) and high copy (h.c.) numbers. In these strains, the native SUP70 allele was present, allowing the effect of pus1 mutation on sup70-65 function to be studied. As described earlier, high-copy expression of sup70-65 is required to enable robust growth on trp-, whereas single-copy expression permits substantially weaker growth (Figure 5B) [40]. When we assessed the impact of elevated temperature, we observed a gradual decline in UAG suppression enabling growth on trp- medium. At $34{ }^{\circ} \mathrm{C}$, no growth was observable with s.c. expression of sup70-65 and at $37^{\circ} \mathrm{C}$, even h.c. sup70-65 failed to provide tryptophan prototrophy (Figure 5B). Since the reporter strains grew normally on tryptophan-supplemented control plates, these differences were attributable to changes in UAG decoding required for Trp1 expression from the trp1-1 allele. Thus, mildly elevated temperature reduced the UAG decoding potential of sup70-65.
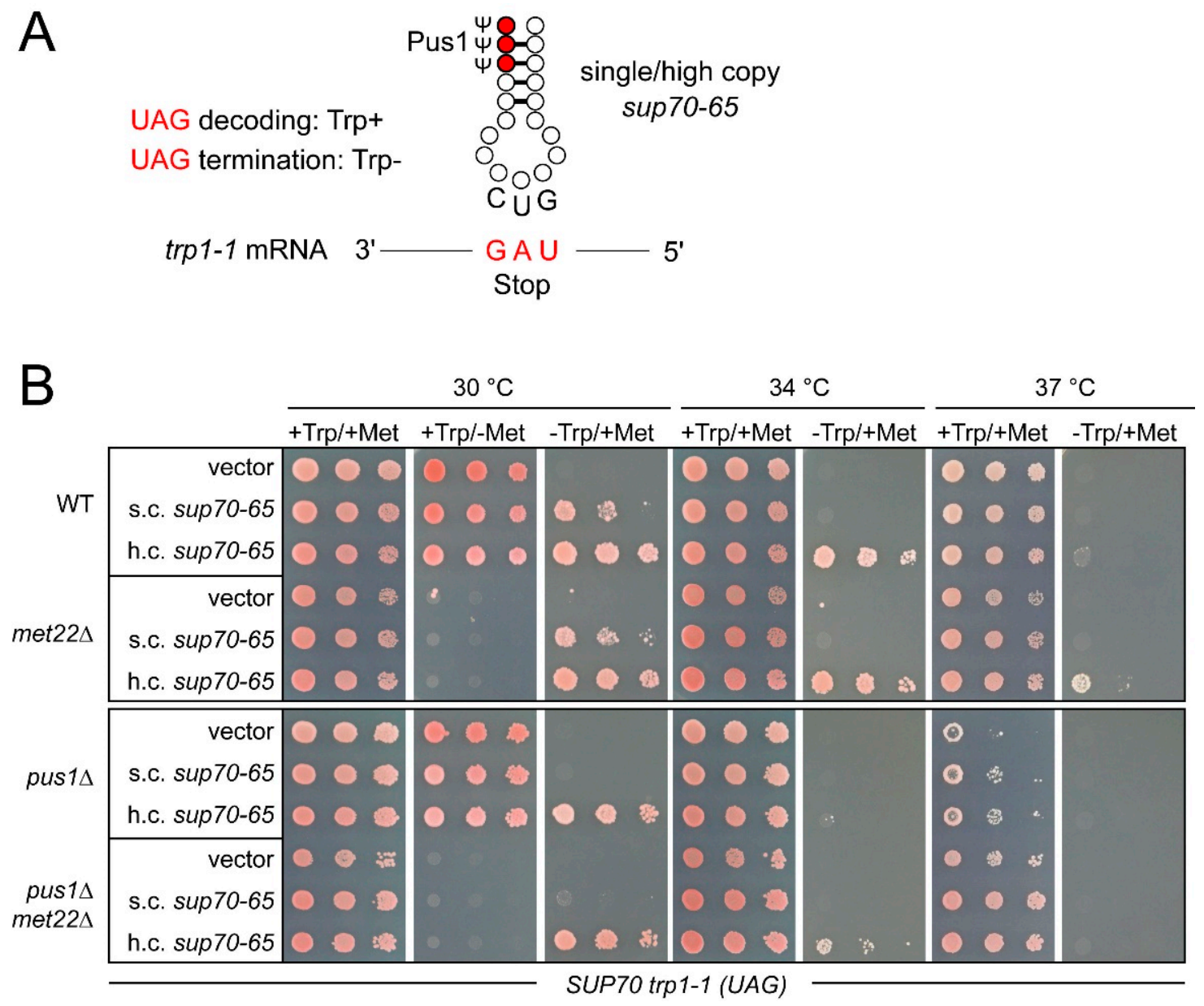

Figure 5. UAG decoding by sup70-65 in absence of PUS1 and MET22. (A) Scheme depicting the first codon position U/G error in the decoding of UAG stop codons by sup70-65. In the trp1-1 allele, a premature UAG codon abrogates translation of the trp1-1 mRNA, leading to tryptophan auxotrophy (Trp-). In the presence of sup70-65 in single or high copy numbers, UAG readthrough occurs, leading to a partial or full reversion of tryptophan auxotrophy (Trp+) associated with the trp1-1 allele. (B) Assessment of UAG readthrough by sup70-65 in single copy (s.c.) or high copy (h.c.) numbers at different temperatures and in the absence of MET22, PUS1, or both. +Trp/+Met refers to minimal medium supplemented with both methionine and tryptophan (control), -Trp/+Met medium allowed UAG readthrough to be determined, and +Trp/-Met medium was employed as a phenotypic control for the presence of the met 22 mutation that causes methionine auxotrophy. 
When sup70-65-mediated UAG decoding was scored in the presence of the pus1 mutation, a clear negative impact of the modification defect became apparent (Figure 5B). In contrast to the wild-type at $30{ }^{\circ} \mathrm{C}$, s.c. sup $70-65$ was insufficient in pus1 mutants to enable growth on trp- medium. At elevated temperatures $\left(34^{\circ} \mathrm{C}\right.$ and $\left.37{ }^{\circ} \mathrm{C}\right)$, neither the s.c. nor the h.c. expression of sup70-65 resulted in an ability of the pus1 mutant to grow on trp- medium. Hence, sup70-65-mediated UAG decoding was impaired by the loss of PUS1. The differences in growth on trp- at $30{ }^{\circ} \mathrm{C}$ and $34{ }^{\circ} \mathrm{C}$ were indeed due tryptophan auxotrophy and not due to general growth defects, since normal growth was observed on the tryptophan-supplemented control plates (Figure 5B). Only at $37^{\circ} \mathrm{C}$ did a mild growth inhibition of the pus1 mutant become apparent.

Interestingly, the MET22 deletion resulted in a partial suppression of the UAG-decoding defects observed. At $34{ }^{\circ} \mathrm{C}$, pus 1 met 22 double mutants carrying h.c. sup70-65, but not the pus1 single mutant with the same vector, were able to grow weakly on trp- medium. Weak growth on this medium at $37^{\circ} \mathrm{C}$ was also observed for the met 22 single mutant, but not for the wild-type carrying h.c. sup 70-65. These observations suggest that modest temperature increases gradually impaired the UAG-decoding ability of sup 70-65. This effect was aggravated in the absence of Pus1 and partially suppressed by the RTD-ablating met22 mutation. Hence, not only the cognate CAG-decoding ability of sup70-65, but also the efficiency in UAG mistranslation appeared to be affected by Pus1 in a similar way.

\subsection{Role of PUS1 and MET22 in Paromomycin-Induced Mistranslation}

Since Pus1-dependent pseudouridine is present in several tRNAs, it may positively affect not only sup70 variants but also other tRNAs, and thereby influence translational fidelity. To assess this potential role of Pus1, we utilized a well characterized dual luciferase reporter system to quantify basal and paromomycin-induced mistranslation [35,45]. In this assay, incorporation of histidine by tRNA ${ }^{\text {His }}$ GUG is measured at the CGC (Arg) codon in firefly luciferase. It was previously shown that this misreading event is triggered in vivo by the aminoglycoside paromomycin $[35,45]$. Since the natural CGC decoder tRNA ${ }^{A r g}$ ICG contains Pus1-dependent $\Psi$, but not the mistranslating tRNA ${ }^{\text {His }}$ GUG [14], this assay provided an opportunity to determine the effect of the modification on the competition between both tRNAs for CGC decoding.

We introduced a dual luciferase (renilla/firefly) construct carrying a CAC (His245) to CGC (Arg245) codon substitution in the firefly luciferase gene, as well a control construct expressing unmodified luciferases into the wild-type and pus1 mutants. The dual luciferase reporter and normalization against the control dual luciferase construct without the H245R substitution allowed the measurement of specific CGC misreading rates by $t R N A{ }^{\text {His }}$ GUG and eliminated any potential impact of mRNA abundance changes on the calculated error rates [35]. Interestingly, the absence of PUS1 caused a significant increase (4.3-fold) in basal CGC misreading, which was, however, not suppressed by additional mutation of MET22 (Figure 6). When paromomycin was added during cultivation $(200 \mu \mathrm{g} / \mathrm{mL})$, we observed increased in error rates in both wild-type and the pus1 mutant. The latter again showed significantly increased ( 3.6-fold) CGC mistranslation as compared to the wild-type in the same condition, without a decline in the pus1 met22 double mutant. However, when the aminoglycoside was applied at an elevated temperature $\left(37^{\circ} \mathrm{C}\right), \mathrm{CGC}$ misreading in the pus 1 mutant was further increased and this effect was dependent on the presence of MET22, since misreading rates in the pus1 met22 double mutant were significantly lower (Figure 6). These results revealed that Pus1-dependent $\Psi$ is involved in the prevention of translational errors at the CGC codon, likely due to a positive contribution of the modification to the efficiency of the natural CGC decoder tRNA ${ }^{\mathrm{Arg}}$ ICG. Since met 22 effects were observed for paromomycin-induced mistranslation at elevated temperature, the positive role of Pus1 may in part involve protection from RTD-mediated decay. 


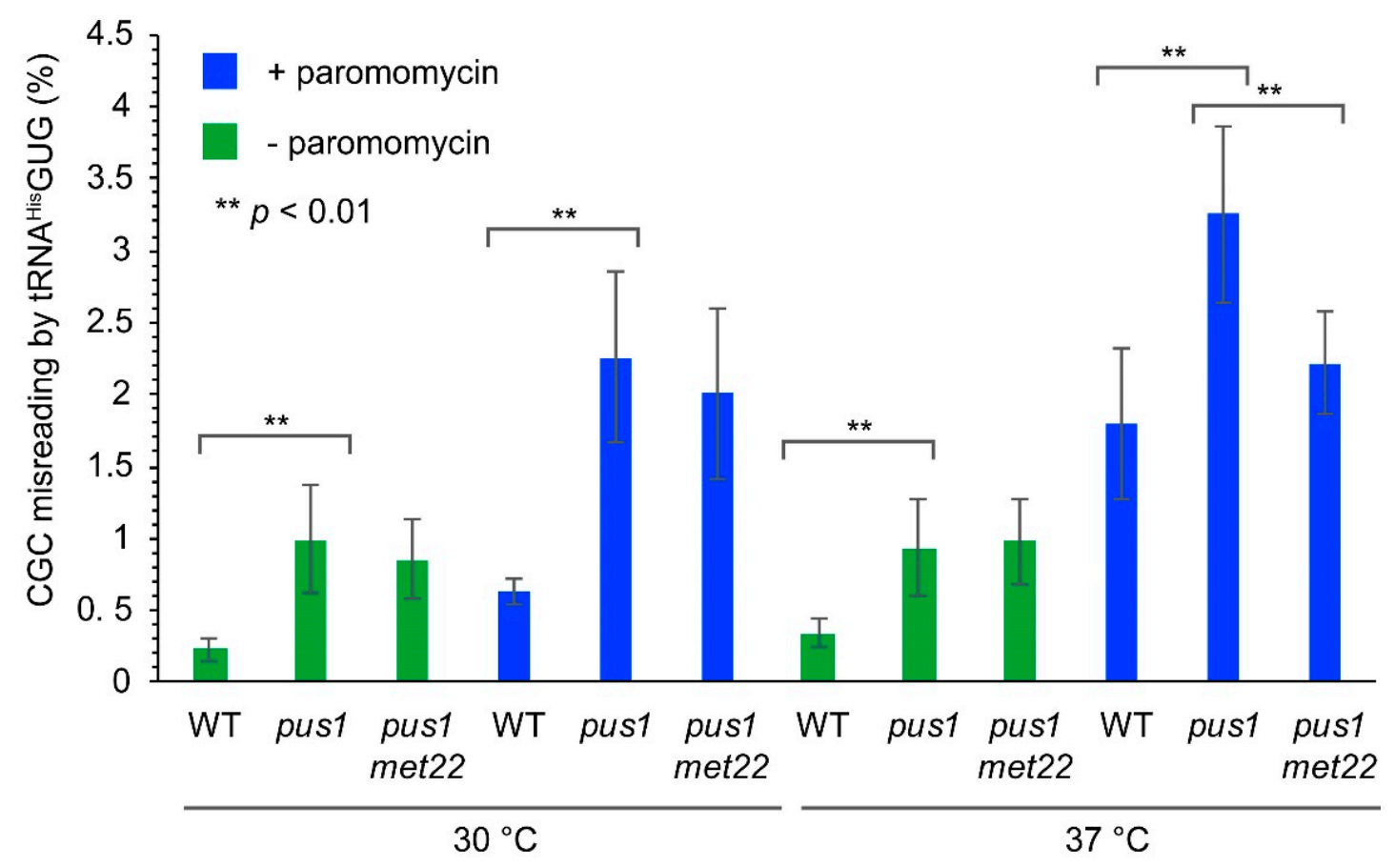

Figure 6. CGC misreading levels in pus1 mutants. Indicated strains were each transformed with two dual luciferase constructs (renilla/firefly control pDB688 and renilla/firefly-H245R pDB868). Strains were cultivated at the indicated temperature and in the presence or absence of $200 \mu \mathrm{g} / \mathrm{mL}$ paromomycin. At least six independent measurements were conducted for each strain/condition Two-tailed Students' $t$-test was utilized to determine statistical significance $\left.{ }^{* *}: p<0.01\right)$.

\section{Discussion}

Pseudouridine represents the most abundant tRNA modification and, in general, it is thought to stabilize the tertiary structure of the tRNA and improve base stacking [1]. However, the occurrence of this modification in multiple positions, including loop and stem regions of the tRNA, may have distinct functional consequences. We focused on the role of Pus1-dependent pseudouridylation for tRNA function in vivo. While in yeast, Pus1 and its modification are dispensable per se [11], it becomes critical when tRNA ${ }^{\text {Gln }}$ CUG is compromised by mismatches in the acceptor (sup70-33) or anticodon stems (sup70-65). These sup70 alleles encode destabilized forms of tRNA ${ }^{\text {Gln }}$ CUG which provide reduced ability to carry out CAG decoding as the essential function of $S U P 70[31,37,38]$. When combining a pus1 mutation with either sup70-33 or sup70-65, synthetic lethality occurs, which can be attributed to a further aggravated CAG-decoding defect. A similar synthetic lethal genetic interaction was previously demonstrated for pus1 and the slc58 allele, encoding another tRNA ${ }^{\text {Gln }} \mathrm{CUG}$ variant with a mismatch destabilizing the T-stem [16]. Hence, Pus1-dependent pseudouridylation likely represents a stabilizing factor that becomes particularly relevant for tRNA ${ }^{\text {Gln }}$ CUG function when stability of the tRNA is compromised otherwise. Similarly, Deg1-dependent psedouridylation at position 38 (anticodon loop) becomes critical for tRNA ${ }^{\text {Gln }}$ CUG function only when the anticodon stem destabilizing sup70-65 mutation is present [40]. In contrast to the Deg1-dependent $\Psi 38$ [46], Pus1-dependent $\Psi 26-28$ does not appear to be crucial for the major Gln isoacceptor tRNA ${ }^{\text {ln }} U U G$, as $t Q(U U G)$ overexpression suppressed the inviability of a sup70 mutant in absence of $P U S 1$. Since $t Q(U U G)$ is very inefficient in CAG decoding [39], any further impairment should be detrimental, which is, however, not observed in absence of Pus1. Hence, the different $\Psi$ formed by Pus1 and Deg1 are of different importance for the two Gln isoacceptor tRNAs. It was speculated previously that Deg1-dependent $\Psi$ is specifically important due to its potential contribution to the stabilization of the anticodon loop [40,47]. Since Pus1-dependent $\Psi$ is localized in the anticodon stem of $\mathrm{tRNA}^{\mathrm{Gln}}$, a distinct functional contribution appears plausible. 
The tRNA overexpression approach shown in Figure S2 suggests that additional tRNAs or other RNA species modified by Pus1 may contribute to the mutant phenotype.

Interestingly, in other tRNAs, stem mismatches and loss of different modifications outside of the anticodon loop may trigger rapid tRNA decay (RTD) [18]. Temperature is recognized as an important factor in RTD, since in several hypomodified or structurally destabilized tRNAs, full decay is induced after modest temperature increases [18,41,42,48]. However, neither of the described tRNA ${ }^{\text {Gln }}$ CUG-destabilizing mutations nor the Pus1-dependent $\Psi$ were known to represent RTD-relevant factors. Since tRNA ${ }^{\text {Ser }}$ and $t R N A^{T y r}$ derivatives with stem mismatches become susceptible to RTD [41-44], a similar effect in sup70-33 and sup70-65 appeared to be possible. Thus, we investigated the potential suppression by met 22 mutation, which broadly inhibits RTD [26,41,43,44,48].

Loss of Pus1 or destabilization of tRNA ${ }^{\text {Gln }}$ CUG is correlated with increased temperature sensitivity and we indeed observed partial suppression of these phenotypes by met22 mutation. In addition, the synthetic lethality caused by combining the pus1 defect and acceptor/anticodon stem mismatches in tRNA ${ }^{\text {Gln }}$ CUG was suppressed by met 22 mutation, which suggests that the observed phenotypes are linked to RTD. In support of this idea, we demonstrated that the sup70-33 variant is further destabilized in vivo by mild heat and this effect is suppressible by met22 mutation. Since the pus1but not the deg1-linked ts phenotype was suppressed by met22 mutation, Deg1-dependent $\Psi$ located in the anticodon loop and anticodon stem base may be much less RTD-relevant as compared to the Pus1-dependent $\Psi$ found in multiple positions. Further work will be required to identify additional tRNAs that rely on Pus1-dependent $\Psi$ for protection against RTD.

In addition to its essential role in CAG decoding, sup70-65 can also misread UAG stop codons via first codon position $U / G$ wobble, possibly due to a change in the structure and orientation of the anticodon loop in response to the mutation in the anticodon stem [31]. Our diagnosis of UAG suppression by sup70-65 revealed a clear negative influence of mildly elevated temperature. Loss of Pus1 had a similar negative effect on UAG decoding by sup70-65, indicating that Pus1 positively contributes to the UAG mistranslating ability of the tRNA. Thus, it appears that Pus1 positively contributes to both misreading and cognate decoding. Similar effects were described for wobble uridine modifications, which support both the decoding efficiency in normal translation and near-cognate misreading [49-53], pointing to a general positive role of different tRNA modifications in tRNA function. Deg1-dependent $\Psi$ was also found to improve stop codon readthrough by natural suppressor tRNAs [54], which may be consistent with an important role of the modification in anticodon loop stabilization supporting both regular decoding and stop codon misreading. In contrast, no effect of Pus1 on UAG readthrough by natural suppressor tRNA was observed [54], which is consistent with our data showing that Pus1 becomes critical for tRNA ${ }^{\text {Gln }}$ CUG function specifically when stem regions are destabilized.

When the effect of met 22 mutation on UAG misreading by sup70-65 was studied, mild suppression of the negative effects of elevated temperature and pus1 mutation were observed. However, suppression in met 22 and pus1 met 22 strains was incomplete, suggesting that even when RTD is inhibited, both increased temperature and loss of Pus1 have negative consequences for sup70-65 function in UAG mistranslation. We assume that Pus1 may fulfil additional and potentially more direct decoding relevant functions in tRNA beyond the protection from RTD. Interestingly, diploid yeast strains carrying homozygous sup70-65 or sup70-33 alleles display disturbed nitrogen signaling and inappropriate filamentous growth responses $[31,38,55]$. If these effects are linked to the destabilization of $t$ RNA ${ }^{\text {Gln }}$ CUG, they may be suppressed by inhibition of RTD, similarly to the ts phenotypes investigated in this study. Nitrogen signaling defects might also contribute to some extent to the ts phenotypes of the sup70 alleles, in addition to the established impairment in CAG decoding.

The presence of Pus1-dependent $\Psi$ in additional $t R N A s$ and the absence of the suppression of the pus1 ts phenotype by $\mathrm{tRNA}{ }^{\mathrm{Gln}}$ overexpression argues for a positive role of the modification in additional tRNAs. Indeed, the absence of Pus1 significantly elevated misreading of CGC (Arg) codons by tRNA ${ }^{\text {His }}$. In this misreading event, the normal CGC decoder tRNA ${ }^{A r g}$ ICG contained Pus1-dependent $\Psi$, but not the mistranslating $\mathrm{tRNA}^{\mathrm{His}}$ [14]. Hence, in tRNA ${ }^{\mathrm{Arg}} \mathrm{ICG}_{\mathrm{C}}$ Pus1-dependent pseudouridylation likely 
represents an important factor to support competition against a tRNA carrying an incorrect near-cognate anticodon (U/G in 2nd codon position). Since the mistranslation rates were similar at both $30^{\circ} \mathrm{C}$ and $37^{\circ} \mathrm{C}$ and in both conditions were unaffected by met 22 mutation, the positive effect of Pus 1 in tRNA ${ }^{A r g}$ ICG may involve other mechanisms than protection from RTD-mediated decay. However, at $37^{\circ} \mathrm{C}$, a further increase of paromomycin-induced mistranslation in the pus1 mutant relative to the wild-type under the same conditions was observed. In contrast to basal mistranslation, this effect was suppressed in the pus1 met22 double mutant. This result suggests that at elevated temperature, Pus1-dependent $\Psi$ limits aminoglycoside-induced mistranslation in part via RTD-protective effects of the modification. We assume that Pus1 contributes to the efficiency of the $t$ RNA ${ }^{\text {Arg }}$ ICG in different ways, presumably including RTD-dependent and -independent mechanisms. Further work will be required to define the effect of the abundant Pus1-dependent $t$ RNA modification on the in vivo function of additional tRNAs and to distinguish between RTD-dependent and -independent effects.

\section{Conclusions}

The importance of Pus1-dependent pseudouridylation for specific in vivo decoding events was analyzed. We focused on tRNA ${ }^{\text {Gln }}$ CUG, since this tRNA is essential in yeast and encoded by a single-copy gene, facilitating genetic approaches. Mutations destabilizing the anticodon or acceptor stem of tRNA ${ }^{\text {Gln }}$ CUG resulted in synthetic lethality upon combination with a PUS1 deletion, suggesting that the essential function in CAG decoding by these tRNA variants cannot be maintained in absence of Pus1-dependent $\Psi$. Phenotypes associated with pus1 mutation, destabilized tRNA ${ }^{\mathrm{Gln}} \mathrm{CUG}$, and the negative genetic interaction of both were suppressed by mutation of the rapid tRNA decay gene MET22. Pus1-dependent $\Psi$ was also required for efficient UAG mistranslation by a $\mathrm{RNA}^{\mathrm{Gln}} \mathrm{CUG}$ variant, revealing a general positive role of the modification in tRNA function. Consistent with this, we demonstrated that Pus1-dependent $\Psi$ improves the ability of a distinct tRNA to compete against mistranslation by a non-synonymous near-cognate tRNA. Our study provides insight into the contribution of Pus1-dependent pseudouridylation to in vivo tRNA function, which likely includes, but is not limited to the prevention of rapid tRNA decay.

Supplementary Materials: The following are available online at http://www.mdpi.com/2218-273X/10/5/729/s1, Figure S1: Thermosensitive growth of deg1 mutants is not rescued by met22 mutation., Figure S2: tRNA overexpression in pus1 mutants, Figure S3: Specificity of sup70-33 detection. Table S1: Oligonucleotides used in this study.

Author Contributions: Conceptualization, R.K. and B.K.; investigation, R.K. and B.K.; writing-original draft preparation, R.K.; writing-review and editing, R.K. and B.K.; funding acquisition, R.K. All authors have read and agreed to the published version of the manuscript.

Funding: This research was funded by Deutsche Forschungsgemeinschaft (DFG) and their Priority Programme SPP1784 'Chemical Biology of Native Nucleic Acid Modifications' to R.K. (KL2937/1-2) and by the University of Kassel graduate school program Biological clocks.

Acknowledgments: We thank D. Bedwell and I. Stansfield for providing plasmids.

Conflicts of Interest: The authors declare no conflict of interest. The funders had no role in the design of the study; in the collection, analyses, or interpretation of data; in the writing of the manuscript, or in the decision to publish the results.

\section{References}

1. Spenkuch, F.; Motorin, Y.; Helm, M. Pseudouridine: Still mysterious, but never a fake (uridine)! RNA Biol. 2014, 11, 1540-1554. [CrossRef] [PubMed]

2. Motorin, Y.; Helm, M. Methods for RNA Modification Mapping Using Deep Sequencing: Established and New Emerging Technologies. Genes (Basel) 2019, 10. [CrossRef] [PubMed]

3. Rintala-Dempsey, A.C.; Kothe, U. Eukaryotic stand-alone pseudouridine synthases - RNA modifying enzymes and emerging regulators of gene expression? RNA Biol. 2017, 14, 1185-1196. [CrossRef]

4. Hawer, H.; Hammermeister, A.; Ravichandran, K.E.; Glatt, S.; Schaffrath, R.; Klassen, R. Roles of Elongator Dependent tRNA Modification Pathways in Neurodegeneration and Cancer. Genes (Basel) 2018, 10. [CrossRef] 
5. McKenney, K.M.; Rubio, M.A.T.; Alfonzo, J.D. The Evolution of Substrate Specificity by tRNA Modification Enzymes. Enzymes 2017, 41, 51-88. [CrossRef]

6. Lecointe, F.; Simos, G.; Sauer, A.; Hurt, E.C.; Motorin, Y.; Grosjean, H. Characterization of yeast protein Deg1 as pseudouridine synthase (Pus3) catalyzing the formation of psi 38 and psi 39 in tRNA anticodon loop. J. Biol. Chem. 1998, 273, 1316-1323. [CrossRef]

7. Chou, H.-J.; Donnard, E.; Gustafsson, H.T.; Garber, M.; Rando, O.J. Transcriptome-wide Analysis of Roles for tRNA Modifications in Translational Regulation. Mol. Cell 2017, 68, 978-992.e4. [CrossRef]

8. Mülleder, M.; Calvani, E.; Alam, M.T.; Wang, R.K.; Eckerstorfer, F.; Zelezniak, A.; Ralser, M. Functional Metabolomics Describes the Yeast Biosynthetic Regulome. Cell 2016, 167, 553-565.e12. [CrossRef]

9. Bozaquel-Morais, B.L.; Vogt, L.; D'Angelo, V.; Schaffrath, R.; Klassen, R.; Montero-Lomelí, M. Protein Phosphatase Sit4 Affects Lipid Droplet Synthesis and Soraphen A Resistance Independent of Its Role in Regulating Elongator Dependent tRNA Modification. Biomolecules 2018, 8. [CrossRef]

10. Motorin, Y.; Keith, G.; Simon, C.; Foiret, D.; Simos, G.; Hurt, E.; Grosjean, H. The yeast tRNA:pseudouridine synthase Pus1p displays a multisite substrate specificity. RNA 1998, 4, 856-869. [CrossRef]

11. Simos, G.; Tekotte, H.; Grosjean, H.; Segref, A.; Sharma, K.; Tollervey, D.; Hurt, E.C. Nuclear pore proteins are involved in the biogenesis of functional tRNA. EMBO J. 1996, 15, 2270-2284. [CrossRef]

12. Behm-Ansmant, I.; Massenet, S.; Immel, F.; Patton, J.R.; Motorin, Y.; Branlant, C. A previously unidentified activity of yeast and mouse RNA:pseudouridine synthases 1 (Pus1p) on tRNAs. RNA 2006, 12, 1583-1593. [CrossRef]

13. Behm-Ansmant, I.; Urban, A.; Ma, X.; Yu, Y.-T.; Motorin, Y.; Branlant, C. The Saccharomyces cerevisiae U2 snRNA:pseudouridine-synthase Pus7p is a novel multisite-multisubstrate RNA:Psi-synthase also acting on tRNAs. RNA 2003, 9, 1371-1382. [CrossRef]

14. Boccaletto, P.; Machnicka, M.A.; Purta, E.; Piatkowski, P.; Baginski, B.; Wirecki, T.K.; de Crécy-Lagard, V.; Ross, R.; Limbach, P.A.; Kotter, A.; et al. MODOMICS: A database of RNA modification pathways. 2017 update. Nucleic Acids Res. 2018, 46, D303-D307. [CrossRef]

15. Gustavsson, M.; Ronne, H. Evidence that tRNA modifying enzymes are important in vivo targets for 5-fluorouracil in yeast. RNA 2008, 14, 666-674. [CrossRef]

16. Grosshans, H.; Lecointe, F.; Grosjean, H.; Hurt, E.; Simos, G. Pus1p-dependent tRNA pseudouridinylation becomes essential when tRNA biogenesis is compromised in yeast. J. Biol. Chem. 2001, 276, 46333-46339. [CrossRef]

17. Sokołowski, M.; Klassen, R.; Bruch, A.; Schaffrath, R.; Glatt, S. Cooperativity between different tRNA modifications and their modification pathways. Biochim. Biophys. Acta 2017. [CrossRef]

18. Alexandrov, A.; Chernyakov, I.; Gu, W.; Hiley, S.L.; Hughes, T.R.; Grayhack, E.J.; Phizicky, E.M. Rapid tRNA decay can result from lack of nonessential modifications. Mol. Cell 2006, 21, 87-96. [CrossRef]

19. Klassen, R.; Grunewald, P.; Thüring, K.L.; Eichler, C.; Helm, M.; Schaffrath, R. Loss of anticodon wobble uridine modifications affects tRNA(Lys) function and protein levels in Saccharomyces cerevisiae. PLoS ONE 2015, 10, e0119261. [CrossRef]

20. Klassen, R.; Ciftci, A.; Funk, J.; Bruch, A.; Butter, F.; Schaffrath, R. tRNA anticodon loop modifications ensure protein homeostasis and cell morphogenesis in yeast. Nucleic Acids Res. 2016, 44, 10946-10959. [CrossRef]

21. Klassen, R.; Schaffrath, R. Collaboration of tRNA modifications and elongation factor eEF1A in decoding and nonsense suppression. Sci. Rep. 2018, 8, 12749. [CrossRef]

22. Björk, G.R.; Huang, B.; Persson, O.P.; Byström, A.S. A conserved modified wobble nucleoside $\left(\mathrm{mcm}^{5} \mathrm{~s}^{2} \mathrm{U}\right)$ in lysyl-tRNA is required for viability in yeast. RNA 2007, 13, 1245-1255. [CrossRef] [PubMed]

23. Pollo-Oliveira, L.; Klassen, R.; Davis, N.; Ciftci, A.; Bacusmo, J.M.; Martinelli, M.; DeMott, M.S.; Begley, T.J.; Dedon, P.C.; Schaffrath, R.; et al. Loss of Elongator- and KEOPS-Dependent tRNA Modifications Leads to Severe Growth Phenotypes and Protein Aggregation in Yeast. Biomolecules 2020, 10. [CrossRef] [PubMed]

24. Bykhovskaya, Y.; Casas, K.; Mengesha, E.; Inbal, A.; Fischel-Ghodsian, N. Missense mutation in pseudouridine synthase 1 (PUS1) causes mitochondrial myopathy and sideroblastic anemia (MLASA). Am. J. Hum. Genet. 2004, 74, 1303-1308. [CrossRef] [PubMed]

25. Phizicky, E.M.; Alfonzo, J.D. Do all modifications benefit all tRNAs? FEBS Lett. 2010, 584, 265-271. [CrossRef]

26. Chernyakov, I.; Whipple, J.M.; Kotelawala, L.; Grayhack, E.J.; Phizicky, E.M. Degradation of several hypomodified mature tRNA species in Saccharomyces cerevisiae is mediated by Met22 and the $5^{\prime}-3^{\prime}$ exonucleases Rat1 and Xrn1. Genes Dev. 2008, 22, 1369-1380. [CrossRef] 
27. Murguía, J.R.; Bellés, J.M.; Serrano, R. The yeast HAL2 nucleotidase is an in vivo target of salt toxicity. J. Biol. Chem. 1996, 271, 29029-29033. [CrossRef]

28. Sherman, F. Getting started with yeast. Meth. Enzymol. 2002, 350, 3-41.

29. Gietz, R.D.; Schiestl, R.H. High-efficiency yeast transformation using the LiAc/SS carrier DNA/PEG method. Nat. Protoc. 2007, 2, 31-34. [CrossRef]

30. Gueldener, U.; Heinisch, J.; Koehler, G.J.; Voss, D.; Hegemann, J.H. A second set of loxP marker cassettes for Cre-mediated multiple gene knockouts in budding yeast. Nucleic Acids Res. 2002, 30, e23. [CrossRef]

31. Kemp, A.J.; Betney, R.; Ciandrini, L.; Schwenger, A.C.M.; Romano, M.C.; Stansfield, I. A yeast tRNA mutant that causes pseudohyphal growth exhibits reduced rates of CAG codon translation. Mol. Microbiol. 2013, 87, 284-300. [CrossRef] [PubMed]

32. Klassen, R.; Paluszynski, J.P.; Wemhoff, S.; Pfeiffer, A.; Fricke, J.; Meinhardt, F. The primary target of the killer toxin from Pichia acaciae is tRNA(Gln). Mol. Microbiol. 2008, 69, 681-697. [CrossRef] [PubMed]

33. Bruch, A.; Klassen, R.; Schaffrath, R. Unfolded Protein Response Suppression in Yeast by Loss of tRNA Modifications. Genes (Basel) 2018, 9. [CrossRef]

34. Fiorentini, P.; Huang, K.N.; Tishkoff, D.X.; Kolodner, R.D.; Symington, L.S. Exonuclease I of Saccharomyces cerevisiae functions in mitotic recombination in vivo and in vitro. Mol. Cell. Biol. 1997, 17, 2764-2773. [CrossRef] [PubMed]

35. Salas-Marco, J.; Bedwell, D.M. Discrimination between defects in elongation fidelity and termination efficiency provides mechanistic insights into translational readthrough. J. Mol. Biol. 2005, 348, 801-815. [CrossRef]

36. Weiss, W.A.; Friedberg, E.C. Normal yeast tRNA(CAGGln) can suppress amber codons and is encoded by an essential gene. J. Mol. Biol. 1986, 192, 725-735. [CrossRef]

37. Gorgoni, B.; Ciandrini, L.; McFarland, M.R.; Romano, M.C.; Stansfield, I. Identification of the mRNA targets of tRNA-specific regulation using genome-wide simulation of translation. Nucleic Acids Res. 2016, 44, 9231-9244. [CrossRef]

38. Murray, L.E.; Rowley, N.; Dawes, I.W.; Johnston, G.C.; Singer, R.A. A yeast glutamine tRNA signals nitrogen status for regulation of dimorphic growth and sporulation. Proc. Natl. Acad. Sci. USA 1998, 95, 8619-8624. [CrossRef]

39. Johansson, M.J.O.; Esberg, A.; Huang, B.; Björk, G.R.; Byström, A.S. Eukaryotic wobble uridine modifications promote a functionally redundant decoding system. Mol. Cell. Biol. 2008, 28, 3301-3312. [CrossRef]

40. Klassen, R.; Schaffrath, R. Role of Pseudouridine Formation by Deg1 for Functionality of Two Glutamine Isoacceptor tRNAs. Biomolecules 2017, 7. [CrossRef]

41. Guy, M.P.; Young, D.L.; Payea, M.J.; Zhang, X.; Kon, Y.; Dean, K.M.; Grayhack, E.J.; Mathews, D.H.; Fields, S.; Phizicky, E.M. Identification of the determinants of tRNA function and susceptibility to rapid tRNA decay by high-throughput in vivo analysis. Genes Dev. 2014, 28, 1721-1732. [CrossRef] [PubMed]

42. Whipple, J.M.; Lane, E.A.; Chernyakov, I.; D'Silva, S.; Phizicky, E.M. The yeast rapid tRNA decay pathway primarily monitors the structural integrity of the acceptor and T-stems of mature tRNA. Genes Dev. 2011, 25, 1173-1184. [CrossRef]

43. Berg, M.D.; Zhu, Y.; Genereaux, J.; Ruiz, B.Y.; Rodriguez-Mias, R.A.; Allan, T.; Bahcheli, A.; Villén, J.; Brandl, C.J. Modulating Mistranslation Potential of tRNA ${ }^{\text {Ser }}$ in Saccharomyces cerevisiae. Genetics 2019, 213, 849-863. [CrossRef]

44. Zimmerman, S.M.; Kon, Y.; Hauke, A.C.; Ruiz, B.Y.; Fields, S.; Phizicky, E.M. Conditional accumulation of toxic tRNAs to cause amino acid misincorporation. Nucleic Acids Res. 2018, 46, 7831-7843. [CrossRef]

45. Kramer, E.B.; Vallabhaneni, H.; Mayer, L.M.; Farabaugh, P.J. A comprehensive analysis of translational missense errors in the yeast Saccharomyces cerevisiae. RNA 2010, 16, 1797-1808. [CrossRef]

46. Han, L.; Kon, Y.; Phizicky, E.M. Functional importance of $\Psi 38$ and $\Psi 39$ in distinct tRNAs, amplified for tRNA $^{\mathrm{Gln}}$ (UUG) by unexpected temperature sensitivity of the $\mathrm{s}^{2} \mathrm{U}$ modification in yeast. RNA 2015, 21, 188-201. [CrossRef]

47. Vendeix, F.A.P.; Murphy, F.V.; Cantara, W.A.; Leszczyńska, G.; Gustilo, E.M.; Sproat, B.; Malkiewicz, A.; Agris, P.F. Human tRNA(Lys3)(UUU) is pre-structured by natural modifications for cognate and wobble codon binding through keto-enol tautomerism. J. Mol. Biol. 2012, 416, 467-485. [CrossRef]

48. Payea, M.J.; Hauke, A.C.; de Zoysa, T.; Phizicky, E.M. Mutations in the anticodon stem of tRNA cause accumulation and Met22-dependent decay of pre-tRNA in yeast. RNA 2020, 26, 29-43. [CrossRef] 
49. Joshi, K.; Bhatt, M.J.; Farabaugh, P.J. Codon-specific effects of tRNA anticodon loop modifications on translational misreading errors in the yeast Saccharomyces cerevisiae. Nucleic Acids Res. 2018. [CrossRef]

50. Ranjan, N.; Rodnina, M.V. Thio-Modification of tRNA at the Wobble Position as Regulator of the Kinetics of Decoding and Translocation on the Ribosome. J. Am. Chem. Soc. 2017, 139, 5857-5864. [CrossRef]

51. Esberg, A.; Huang, B.; Johansson, M.J.O.; Byström, A.S. Elevated levels of two tRNA species bypass the requirement for elongator complex in transcription and exocytosis. Mol. Cell 2006, 24, 139-148. [CrossRef]

52. Nedialkova, D.D.; Leidel, S.A. Optimization of Codon Translation Rates via tRNA Modifications Maintains Proteome Integrity. Cell 2015, 161, 1606-1618. [CrossRef] [PubMed]

53. Rezgui, V.A.N.; Tyagi, K.; Ranjan, N.; Konevega, A.L.; Mittelstaet, J.; Rodnina, M.V.; Peter, M.; Pedrioli, P.G.A. tRNA $\mathrm{t}^{\mathrm{K}} \mathrm{UUU}, \mathrm{t} \mathrm{t}^{\mathrm{Q} U G}$, and $\mathrm{t}^{\mathrm{E}} \mathrm{UUC}$ wobble position modifications fine-tune protein translation by promoting ribosome A-site binding. Proc. Natl. Acad. Sci. USA 2013, 110, 12289-12294. [CrossRef] [PubMed]

54. Lecointe, F.; Namy, O.; Hatin, I.; Simos, G.; Rousset, J.-P.; Grosjean, H. Lack of pseudouridine 38/39 in the anticodon arm of yeast cytoplasmic tRNA decreases in vivo recoding efficiency. J. Biol. Chem. 2002, 277, 30445-30453. [CrossRef] [PubMed]

55. Tate, J.J.; Rai, R.; Cooper, T.G. Nitrogen starvation and TorC1 inhibition differentially affect nuclear localization of the Gln3 and Gat1 transcription factors through the rare glutamine tRNACUG in Saccharomyces cerevisiae. Genetics 2015, 199, 455-474. [CrossRef]

(C) 2020 by the authors. Licensee MDPI, Basel, Switzerland. This article is an open access article distributed under the terms and conditions of the Creative Commons Attribution (CC BY) license (http://creativecommons.org/licenses/by/4.0/). 